\title{
A CLIP TO RETAIN AND SUPPORT NASOTRACHEAL TUBES
}

\author{
D. J. STEWARD, M.B., B.S., D.A., AND A. W. CoNN, M.D., F.R.C.P.(C)
}

Prolonged nasotracheal intubation has become standard practice in respiratory care. A variety of tube designs have been employed for this purpose, and numerous methods of fixation have been described. This paper introduces a new and relatively simple clip which provides firm support and fixation of any nasotracheal tube mounted on a standard $15 \mathrm{~mm}$. straight connector.

The clip consists of two loops of 18 gauge wire joined at their base (see Fig. 1). The upper loop contains a ring which will fit around a $15 \mathrm{~mm}$. connector.

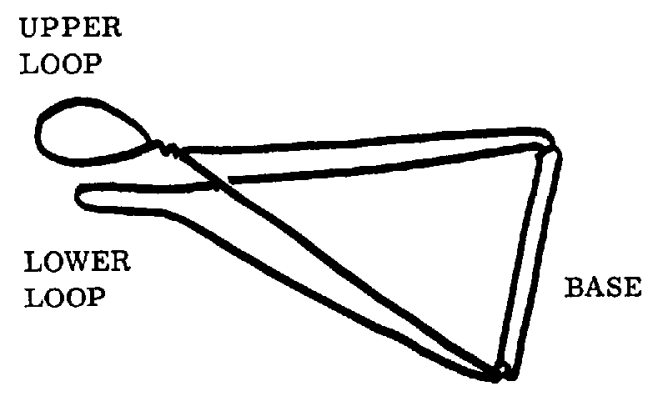

Figure 1. Sketch of the clip.

The lower loop is designed to partially encircle the stem of the connector and the tube.

The clip is attached to the connector and tube as follows. First the two loops are separated slightly. The connector is passed through the wide portion of the lower loop, and the clip drawn back until the two loops can be closed together. The upper loop now fits around the $15 \mathrm{~mm}$. connection, and the lower loop passes around the stem and supports it. This procedure is carried out with the tube in situ, and without removing the connector.

The clip is then secured to the forehead of the patient as shown in Figure 2. The skin is prepared with tincture of benzoin, and a pad of cotton gauze or plastic foam placed on the forehead. The base of the clip is taped over this. A narrow strip of adhesive tape is used to secure the two loops together, thereby maintaining a firm hold on the connector.

It is recommended that the tube itself should be secured to the skin at the nostril with narrow strips of adhesive. This will obviate the possibility of advancement or withdrawal of the tube.

It is considered that the clip described here has the following advantages. Firstly, it may be used on any tube with a $15 \mathrm{~mm}$. straight connector. Secondly,

-Models of this clip which will accommodate tube sizes from $2.5 \mathrm{~mm}$. to $6.5 \mathrm{~mm}$. have been manufactured by Down Brothers and Mayer and Phelps Ltd., 410 Dundas Street West, Toronto 2B, Ontario. 


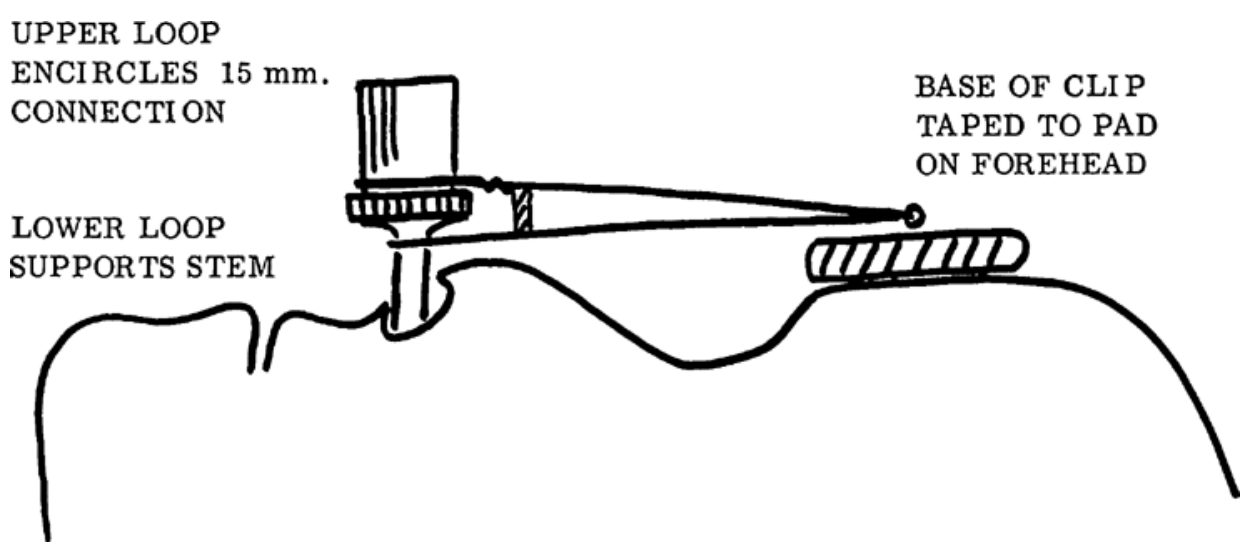

Figure 2. Position of the clip in use.

it may be attached to a tube already in situ, without the need to change the connector. Thirdly, the design of the clip firmly supports the tube as it enters the nostril. Thus movement of the tube within the nasal cavity is minimized. This eliminates the danger of the tube kinking at this site, and helps prevent trauma to the nasal mucous membrane.

This clip has been found very satisfactory in use, and is considered to have its principal application in neonates, infants, and young children, when the use of a thin-walled tube predisposes to movement and kinking.

\section{SUMmary}

A new clip to retain and support nasotracheal tubes is described. The advantages of its use are outlined. 